\title{
Links between oral health and personality at a law enforcement school
}

\section{Research Article}

\author{
Ildikó Faragó ${ }^{1}$, Ferenc Túry², Sándor Márton³, \\ Gábor Nagy ${ }^{4}$, Matthew Hopcraft ${ }^{5}$, Melinda Madléna*6 \\ 1 Miskolc Law Enforcement Secondary School, Szentpétery Gate 78., 3526 Miskolc, Hungary
}

2 Department of Behavioral Medicine, Faculty of Medicine, Semmelweis University, Nagyvarad Square 4., 1089 Budapest, Hungary

3 Department of Sociology and Social Policy, Faculty of Arts, University of Debrecen, Egyetem Square 1., 4032 Debrecen, Hungary

4 Department of Community Dentistry, Section of Oral Diagnostics, Faculty of Dentistry, Semmelweis, University Szentkirályi Street 40., 1088 Budapest, Hungary

5 Melbourne Dental School, The University of Melbourne, Swanston Street 720., Melbourne, Australia

6 Department of Paedodontics and Orthodontics, Faculty of Dentistry, Semmelweis University, Szentkirályi Street 47., Budapest, Hungary

\section{Received 4 April 2013; Accepted 11 June 2013}

Abstract: One of the territories of dental psychosomatics is the link between personality characterisctics and dental status. The aim of the present study was to survey the relationship between temperament and character factors and dental status in police students. It can be hypothesized, that some temperament factors can increase the risk for dental health problems. After dental screening 792 police students completed the Temperament and Character Inventory (TCI) devised by Cloninger. $57.5 \%$ of students rated their own teeth as being in good or very good condition, and only $2.8 \%$ as bad condition. In persons rating their dental status as "good", the average DMFT was $9.23 \pm 5.01$ (mean \pm S.D.). In students assessing their own oral health as bad, TCl results showed that a higher percentage of students displayed extravagance, impulsiveness, disorderliness than the overall population. Among the students with good selfassessment but bad teeth, there was a higher percentage of students displaying passivity, low assertiveness, and introversion. The temperament and character factors may have negative consequences for students in an institution which exposes them to high stress level. It may be useful to screen these students using subjective health questionnaires in order to permit more effective efforts to positive health behaviour.

Keywords: Temperament $\bullet$ Character $\bullet$ Oral health $\bullet$ Caries prevalence $\bullet$ Military population

(C) Versita Sp. z 0.0.

\section{Introduction}

Vocational training for law enforcement agencies in Hungary takes place in special residential schools which students enter after graduating from secondary school. After completing the course, they begin their careers as non-commissioned officers. Training lasts for two years and classes for each year run concurrently.

Processes in the oral cavity are part of everyday life and the signs of external and internal influences quickly become apparent there. External psychogenic factors causing somatic symptoms in the periodontium, the oral mucosa and the temporomandibular joint have been the subject of several studies [1-4]. It is also known that the condition of the periodontium is affected by stress, inappropriate health behaviour and difficult living circumstances [5-7]. However, in the latest 10 years we have found only one paper, on the relationship between den- 
tal health, caries and psychic effects [8].

The reaction of persons with varying temperament and character to these factors may show up in the most diverse psychosomatic phenomena and conditions. Baranyai et al. (2006) found that the knowledge of risk factors may not in itself cause people to avoid harmful phenomena, i.e. the knowledge of hazards can be weakly associated with behaviour [9].

In their psychobiological model, Cloninger et al. (1993) associated temperament and character factors defining the personality type of individuals with various phases of personality development. The theory describes personality using four temperament and three character factors which are measured based on the purpose-designed Temperament and Character Inventory (TCI) [10].

The internationally accepted measure - also used in Hungary - of the number of decayed (D), missing (M) and filled $(F)$ teeth $(T)$ is the DMFT index, and is registered using a $\mathrm{WHO}$-approved form [11]. In the latest years there is only one study giving data on the dental decay of young men called up for military service in Hungary, measured by the attendance at school dentistry service [12]. In a study about recruits to the Australian armed forces, Dawson and Smales (1994) found no correlation between the numbers of filled teeth due to change of dentist [13]. Suman et al. (2008) studied Croatian soldiers in two groups (those who had been deployed in live combat and those who had not) and found the former to have significantly worse oral health [14]. Vered and Sgan-Cohen (2003) examined discrepancies between questionnaire results and physical measurements among 4920 young (21 years old) Israeli people serving compulsory military service, and found that they were not correct or objective in their self-assessment of "good" and "bad" dental status; that is their self-assessment was not appropriate [15].

We could not find any similar Hungarian survey; the closest in subject was a publication involving the Dental Anxiety Scale [16].

The aim of the present study was to survey the temperament and character factors that characterise students recruited to the law enforcement services and their respective dental status. The primary research question was whether temperament and character factors were linked to dental status.

\section{Patients and methods}

The subjects of this study were law enforcement school students who were exposed to a sudden increase in expectations and a new environment imposing a high de- gree of stress and they were also subject to increased physical exertion at the same time.

The study involved 792 law enforcement school students of an average age of $20.43 \pm 1.25$ (mean \pm S.D.) years. The male/female ratio was $715 / 77$. After receiving appropriate information and signing a consent form, the subjects completed, by computer, the Temperament and Character Inventory ( $\mathrm{TCl}$ ) with 240 items devised by Cloninger et al. in 1994 [17]. The bases for interpreting the $\mathrm{TCl}$ results are the standardised scores on the 7 dimensions. Raw scores are converted to standard or T-scores by a special formula. A T-score of 50 is the average of the sample used for standardisation [17]. Between 40-60 T-scores is $68 \%$ of the samples used for standardisation (considering the normal distribution), between 60-70 and $30-40$ T-scores is 14 and $14 \%$ of the sample, above and below these scores is 2 and $2 \%$ of the remaining sample. The 40-60 T-score is called the "average" zone, the 60-70/30-40 T-score is called "strongly above/below average" zone, and over these scores "extreme or very strongly above/below average" zone.

In our study, students' average T-scores were in the average range, between 45 and 55 except for self-directedness, whose T-score was slightly above average, $57.57 \pm 8.43$.

This was preceded by a dental screening where their DMFT was measured [11]. All participants were examined by a single dental examiner (I.F.). The clinical diagnostic criteria for dental caries were visually apparent cavitation, discolouration showing through enamel or visual evidence of recurrent caries. Radiographs were not used in this study.

Besides the cariological screening, participants filled in a questionnaire about their nutritional and oral hygiene habits and certain aspects of family and social background [18]. Caries prevalence and the results of that part of the study have been presented elsewhere. Except for the sick persons, the students were not allowed to refuse participation in dental screening because (according to bylaws) it was compulsory for every police student. However, the filling in of the questionnaire was optional. Nevertheless, they all undertook to answer the questions although not everybody was able to answer them all and there were also invalid answers. The survey was taken between 1 January and 31 March 2008 and was approved by the Semmelweis University Regional and Institutional Committee of Science and Research Ethics (TUKEB 108/2007).

Statistical analysis was carried out using the SPSS for Windows 10.0 program suite and involved descriptive statistical methods (distribution, average, variance), ANOVA tables, Pearson correlation analysis and Cronbach's alpha; the level of significance was set at $p<0.05$. 


\section{Results}

\subsection{Oral health}

$57.5 \%$ of students evaluated their own teeth as being in good or very good condition, and only $2.9 \%$ reported that they were in bad or very bad condition. $39.6 \%$ reported that they were in average condition.

In the comparison of self-assessment and the actual dental status, the average DMFT of those who rated their dental status as "good" was $9.23 \pm 5.01$, their D value being 6.93 \pm 4.27 (Table 1).

Table 1. Relationships between police students' self-assessment of their teeth and DMFT values and its components.

\begin{tabular}{|c|c|c|c|c|c|}
\hline $\begin{array}{l}\text { How do you rate } t \\
\text { status of your teet }\end{array}$ & & D & M & $\mathrm{F}$ & DMF T \\
\hline Very good & $\begin{array}{c}\text { mean } \pm \\
\text { S.D. } \\
N\end{array}$ & $3.54 \pm 3.34$ & $\begin{array}{r}1.83 \pm 1.70 \\
46\end{array}$ & $\begin{array}{l}0.33 \pm 0.94 \\
6\end{array}$ & $5.69 \pm 4.42$ \\
\hline Good & $\begin{array}{c}\text { mean } \\
\pm S . D . \\
N\end{array}$ & $6.93 \pm 4.27$ & $\begin{array}{r}1.73 \pm 1.65 \\
32\end{array}$ & $\begin{array}{l}0.57 \pm 1.05 \\
22\end{array}$ & $9.24 \pm 5.01$ \\
\hline Moderately good & $\begin{array}{c}\text { mean } \pm \\
\text { S.D. } \\
N\end{array}$ & $9.48 \pm 4.79$ & $\begin{array}{r}1.43 \pm 1.49 \\
25\end{array}$ & $\begin{array}{l}1.40 \pm 1.64 \\
54\end{array}$ & $12.32 \pm 5.69$ \\
\hline Bad & $\begin{array}{c}\text { mean } \pm \\
\text { S.D. } \\
N\end{array}$ & $11.53 \pm 4.56$ & $\begin{array}{r}1.76 \pm 1.56 \\
17\end{array}$ & $\begin{array}{l}1.00 \pm 1.22 \\
7\end{array}$ & $14.29 \pm 4.70$ \\
\hline Very bad & $\begin{array}{c}\text { mean } \\
\mathrm{N}\end{array}$ & 20.00 & 2.00 & 1.00 & 23.00 \\
\hline Total & $\begin{array}{c}\text { mean } \pm \\
\text { S.D. } \\
N\end{array}$ & $7.84 \pm 4.79$ & $1.62 \pm 1.59$ & $\begin{array}{l}0.89 \pm 1.38 \\
40\end{array}$ & $10.36 \pm 5.64$ \\
\hline
\end{tabular}

The scores of temperament and character based on the $\mathrm{TCl}$ test of various groups were compared with DMFT values. There were significant differences $(p<0.05)$ between the following groups: students who had extremely strongly below average novelty-seeking $(T)$ scores in the $\mathrm{TCl}$ test had DMFT 11.25 \pm 2.06 (mean \pm S.D.) while those with extremely strongly below-average harm-avoidance temperament scores had DMFT $10.15 \pm 5.76$ and their $D$ values was $8.75 \pm 4.9$ (mean \pm S.D.).

The group of students with extremely high (extremely strongly above average) scores in the reward dependence dimension had a DMFT value of $5.00 \pm 1.24$ (mean \pm S.D.). The group with very high (extremely strongly above average) or low (strongly above average) scores in the self-directedness character dimension had DMFT values of $10.38 \pm 5.80$ and $10.95 \pm 4.60$ (mean \pm S.D.), respectively.

\subsection{Temperament and character dimensions}

Figures 1 and 2 show the distribution of students in the whole and poor-self-assessment group with below-av-

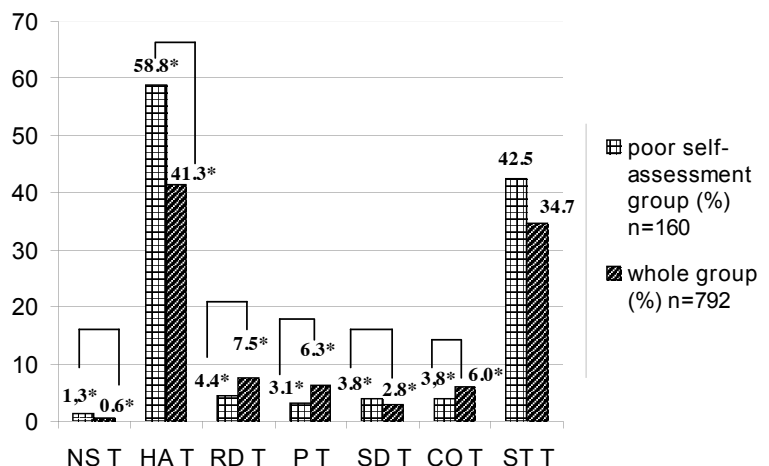

Figure 1. Distribution of students in the whole- and the poor selfassessment group with below-average scores in each $\mathrm{TCl}^{1}$ dimension (\%)

$$
\begin{aligned}
\text { NS T } & =\text { Novelty-Seeking T-score } \\
\text { HA T } & =\text { Harm Avoidance T-score } \\
\text { RDT } & =\text { Reward Dependence T-score } \\
P T & =\text { Persistence T-score } \\
\text { SD T } & =\text { Self-Directedness T-score } \\
\text { COT } & =\text { Cooperativeness T-score } \\
\text { ST T } & =\text { Self-Transcendency T-score }
\end{aligned}
$$

Poor self-assessment group: students who judged their dental status as good but DMFT $>9 * p<0.05$

1:TCl: Temperament and Character Inventory

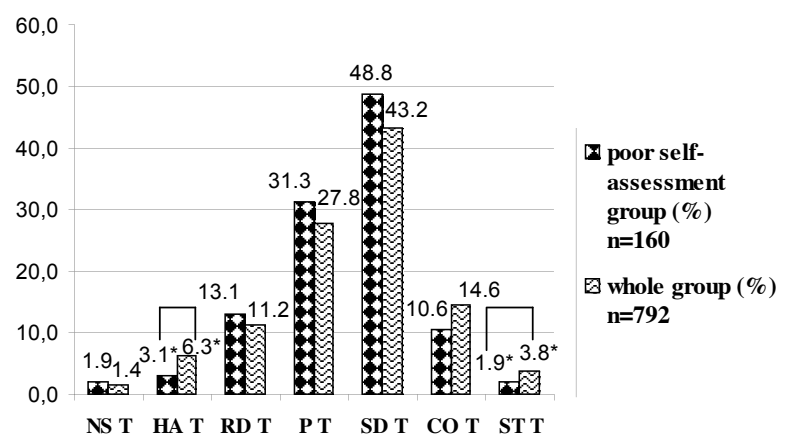

Figure 2. Distribution of students in the whole- and the poor selfassessment group with above-average scores in each $\mathrm{TCl}^{1}$ dimension (\%)

$$
\begin{aligned}
\text { NS T } & =\text { Novelty-Seeking T-score } \\
H A T & =\text { Harm Avoidance T-score } \\
\text { RD T } & =\text { Reward Dependence T-score } \\
P T & =\text { Persistence T-score } \\
\text { SD T } & =\text { Self-Directedness T-score } \\
\text { CO T } & =\text { Cooperativeness T-score } \\
\text { ST T } & =\text { Self-Transcendency T-score }
\end{aligned}
$$

Poor self-assessment group: students who judged their dental status as good but DMFT $>9$

${ }^{*} p<0.05$

${ }^{1}:$ Temperament and Character Inventory

erage and above-average scores in the temperament (novelty seeking, NS; harm avoidance, HA; reward dependence, RD; persistence, $\mathrm{P}$ ) and the character (selfdirectedness, SD; cooperativeness, CO; self-transcendency, ST) dimensions. Figures 3 and 4 demonstrate similar data on the distribution of students in the whole and good-self-assessment group with below and above average scores (Figure 3, 4). 


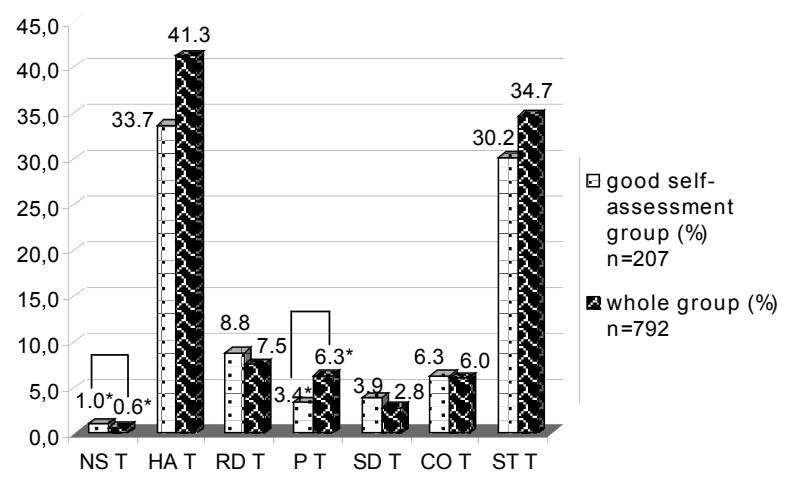

Figure 3. Distribution of students in the whole- and the good selfassessment group with below-average scores in each $\mathrm{TCl}^{1}$ dimension (\%).

$$
\begin{aligned}
\text { NS } T & =\text { Novelty-Seeking T-score } \\
H A T & =\text { Harm avoidance T-score } \\
R D T & =\text { Reward Dependence T-score } \\
P T & =\text { Persistence T-score } \\
\text { SDT } & =\text { Self-Directedness T-score } \\
\text { COT } & =\text { Cooperativeness T-score } \\
\text { ST T } & =\text { Self-Transcendency T-score }
\end{aligned}
$$

Good self-assessment group: students who judged their dental status as bad or very bad, and DMFT $>9$ ${ }^{*} p<0.05$

$1:$ Temperament and Character Inventory

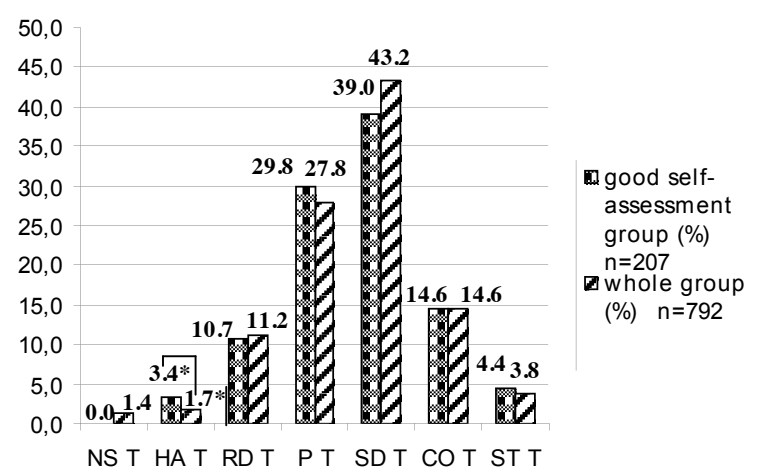

Figure 4. Distribution of students in the whole- and the good selfassessment group with above-average scores in each Temperament and Character Inventory (TCl) dimension (\%).

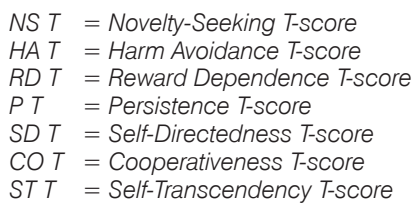

Good self-assessment group: students who judged their dental status as bad or very bad, and DMFT $>9$

${ }^{*} p<0.05$

There were significant $(p<0.05)$ differences between the sexes in empathy (C2), compassion (C4) and reward dependence (RD). Women's average scores were higher in empathy and compassion and those of men were higher in reward dependence $(p<0.05)$. There was also a higher percentage of men $(p<0.05)$ with above- average scores in the novelty-seeking dimension.

The proportion of novelty-seeking scores was slightly higher in the extremely above-average category, and significantly higher $(p<0.05)$ in the extremely below-average category among students who rated their teeth as good or very good but had a DMFT higher than 9 (poor self-assessment group, Group 1), related to the whole study sample (Figure 1, 2).

In Group 1, half as many $(p<0.05)$ were strongly above average in the harm avoidance category than in the study sample as a whole (Figure 2), and a higher percentage was strongly above average in the cooperativeness category compared with the whole sample of students although the difference was not significant (Figure 2).

Significantly lower percentages of their scores for persistence were in the slightly and strongly below average categories $(p<0.05)$. In the self-directedness dimension, the poor self-assessment group had a significantly higher percentage of those who were strongly below average than the overall population. In the cooperativeness character dimension, $3.8 \%$ of Group 1 was strongly below average, compared to $6.0 \%$ of the total number of students. A much lower percentage had scores strongly below average in the reward dependence category $(p<0.05)$. Altogether $1.9 \%$ of students in Group 1 had a self-transcendency T-score strongly above average, compared to $3.8 \%$ of the whole student sample under study.

Group 2 comprised students who stated that their teeth were in bad or average condition and their DMFT was higher than 9 - the good self-assessment group.

Data for Group 2 show significant divergence from the average in the novelty seeking, harm avoidance and persistence categories (Figure 3, 4).

The percentages with extremely low scores in novelty seeking and persistence (Figure 3), and extremely high scores in harm avoidance were significantly higher $(p<0.05)$ than those of the study population as a whole (Figure 4). Group 2 showed no significant divergence from the population as a whole in reward dependence and cooperativeness.

\section{Discussion}

The different responses to stress depend on the individual's personality, temperament and character. The state of the oral cavity (as the gate of the digestive tract) is the product of our everyday life - eating and toothbrushing habits - and strongly reflects our personalities and socio-cultural heritage. This is manifested - in a clearly perceived and objectively measurable way - by various diseases of the teeth, first of all caries. 
It is known that stress and recurrent external negative effects manifest themselves in various psychosomatic conditions $[19,20]$. The purpose of this study was to examine differences in DMFT among people with different personalities, measured in terms of their temperament and character traits. No similar study was found in the international literature. Dental studies carried out in law enforcement bodies found the average DMFT value to be 7.34 [12]. The average caries index measured in the Croatian army was 10.52, and of the 912 soldiers examined, only 14 were found to have completely intact teeth [21]. Among the 792 students surveyed in this study, the average DMFT value was $10.18 \pm 5.78$. No significant difference in DMFT was found between the sexes $(p>0.05)[18]$.

Hopcraft and Morgan (2003) reported that the Australian military was a potentially very large research sample which provided a unique opportunity for examining oral health against various influencing factors and projecting the results to society as a whole [22]. More studies have demonstrated the role of socio-economic background in the formation of caries $[7,20]$, but in the latest literature only one had clearly shown the effect of stress [8]. Suman et al. (2008) investigated the effect of the war on oral health among professional soldiers and found the number of decayed, filled and missing teeth was significantly higher (DMFT 14.4) among those who had been in combat than among those who had not (DMFT 13.1) [14]. Muhvic-Urek et al. (2007) studied dental status of war veterans of the Croatian army suffering from post-traumatic stress disorder and found that they had higher DMFT values than the control group, although the difference was not statistically significant [23]. Vered and Sgan-Cohen (2003) carried out a questionnaire survey on 4920, 21-year-old young Israeli people on compulsory military service, asking them how they assessed the status of their own teeth. A dental screening test was performed at the same time, the average DMFT was $8.34 \pm 4.85$. Altogether $51.41 \%$ of the studied population had DMFT higher than 8.00 , showing their poor dental clinical status. On the contrary, the questionnaire found that only $26 \%$ considered that their teeth were in bad condition. This shows an inadequate evaluation of health and disease and poor selfassessment of dental health. In the present study, the average DMFT was $10.18 \pm 5.78$ - considerably higher than that of the young Israelis in the survey executed 6 years ago [15]. Altogether $57.5 \%$ of the asked people considered that their teeth were in good condition and only $2.7 \%$ considered that they were in bad condition. This implies that the study population had worse oral health and a worse appreciation of their oral health, which means poor self-assessment.

Lencová et al. (2006) took a novel approach to caries prevention: positive "coping" behaviour is important in withstanding stress without injury [19]. Smiling, uninhibited laughter and appropriate diet all have an effect on the quality of life via oral health. This approach, if it can influence both political decision-makers and the population, could be a more effective tool in attaining goals than the presentation of objectively-measured but less comprehensible disease indices. From this point of view, the present results could be useful for preventive purposes.

The data permit some conclusions regarding the link between certain personality traits and DMFT indices. In Group 1 - students who poorly assessed their own oral health - TCl test results found that a higher percentage of students displayed extravagance, impulsiveness, disorderliness than in the overall population of the law enforcement school students studied. This may be the basis for false self-assessment and bad oral hygiene. They could, however, be motivated by reward, and be compassionate and empathic, but their self-transcendency scores showed that a high percentage of these students lacked interpersonal skills.

In Group 2 - good self-assessment but bad teeth - there was a higher percentage of students displaying passivity, low assertiveness, and introversion. In these cases, the knowledge of personality traits allows of more efficient means in preventive communication in the pursuit of convincing students to take better care of their teeth. Overall, the link between high DMFT and certain temperament factors implies, according to Cloninger's theory, that these students have exaggerated self-confidence and persistence, and are characteristically undisciplined and lacking in purpose [17]. Low DMFT - i.e. good oral hygiene - is connected to strong reward dependence, emotional suggestibility, openness and compassion.

In conclusion: The students in this study who had higher caries prevalence, whether they assessed the situation positively or negatively, showed signs of extreme personality traits, and this may have negative consequences for students in an institution which exposes them to heightened levels of stress. It may be useful to screen these students using subjective health survey questionnaires in order to permit more effective efforts to predispose them to positive health behaviour. This kind of prevention could be crucial for law enforcement students, because improving their oral health will bring a positive change to their quality of life and potential benefits for their mental stability. 


\section{References}

[1] Genco R.J., Ho A.W., Grossi S.G., Dunford R.G., Tedesco L.A., Relationship of stress, distress and inadequate coping behaviors to periodontal disease, J Periodontol, 1999 , 70, 711-723

[2] Dumitrescu A.L., Psychological perspectives on the pathogenesis of periodontal disease, Rom J Intern Med, 2006, 44, 241-260

[3] Emodi-Perlman A., Yoffe T., Rosenberg N., Eli I., Alter Z., Winocur E., Prevalence of psychologic, dental, and temporomandibular signs and symptoms among chronic eating disorders patients: a comparative control study, Orofac Pain 2008 , 22, 201-208

[4] Garcia-Pola Vallejo M.J., Martinez Díaz-Canel A.I., Garcia Martin J.M., González Garcia M., Risk factors for oral soft tissue lesions in an adult Spanish population, Community Dent Oral Epidemiol, 2002, 30, 277-285

[5] Cinar A.B., Kosku N., Sandalli N., Murtomaa H., Individual and maternal determinants of self-reported dental health among Turkish school children aged 10-12 years, Community Dent Health, 2008, 25, 84-88

[6] Monteiro da Silva A.M., Newman H.N., Oakley D.A., O'Leary R., Psychosocial factors, dental plaque levels and smoking in periodontitis patients, J. Clin Periodontol, 1998 , 25, 517-523

[7] Hobdell M.H., Oliveira E.R., Bautista R., Myburgh N.G., Lalloo R., Narendran S., Johnson N.W., Oral diseases and socio-economic status (SES), Brit Dent J, 2003, 194, 91-96

[8] Sutton P.R., Psychosomatic dental disease: is mental stress in adults followed by acute dental caries in all racial groups? Med Hypotheses, 1993, 41, 279-281

[9] Baranyai R., Bakos G., Steptoe A., Wardle J., Kopp M., Egyetemisták és főiskolások szívbetegséggel kapcsolatos egészségmagatartása, rizikótudata és hiedelmei. (Health behaviour, risk knowledge and beliefs among university and college students linked with hearth diseases.) Ment Pszichoszom, 2006 , 7, 125-138

[10] Cloninger C.R., Svrakic D.M., Przybeck T.R., A psychobiological model of temperament and character, Arch Gen Psychiatry, 1993, 50, 975-990

[11] World Health Organization: Oral Health Surveys: Basic methods, WHO, Geneva 1997

[12] Vass É.ZS., Milyen az újoncok foga 1995-ben?, (What is the dental condition in new recruits in
1995?) Fogorv Szle, 1997, 90, 267-272

[13] Dawson A.S., Smales R.J., Dental health changes in an Australian Defence Force population, Aus Dent J, 1994 , 39, 242-246

[14] Suman M., Spalj S., Plancak D., Dukic W., Juric H., The influence of war on the oral health of professional soldiers, Int Dent J, 2008, 58, 71-74

[15] Vered Y., Sgan-Cohen H.D., Self-perceived and clinically diagnosed dental and periodontal health status among young adults and their implications for epidemiological surveys, BMC Oral Health, 2003, 3, 1-6

[16] Fábián T.K., Kelemen P., Fábián G., A Dental Anxiety Scale („Fogászati szorongás skála”) hazai bevezetése. Magyar populáción végzett fogászati szorongás epidemiológia vizsgálatok, (Introduction of the concept of Dental Anxiety Scale in Hungary. Epidemiologic studies on the Hungarian population.), Fogorv Szle, 1998, 91, 43-52

[17] Cloninger C.R., Przybeck T.R., Svrakic D.M., Wetzel R.D., The temperament and character inventory ( $\mathrm{TCl}$ ): A guide to its development and use. Washington: St. Louis, MO: Center for Psychobiology of Personality, Washington University, 1994

[18] Faragó I., Nagy G., Márton S., Túry F., Szabó E., Hopcraft M.S., Madléna M., Dental caries experience in Hungarian police student population, Caries Res 2012, 46, 95-101

[19] Lencová E., Broukal Z., Dusková J., Psychosocial, behavioural and oral health indicators - review of the literature, Prague Med Rep, 2006 , 107, 305316

[20] Sirpa A.V., Depressive symptoms in relation to oral health and related facors in a middle-aged population, Analytical approach, Acta Univ. Oul., Academic dissertation, University of Oulu, Oulu, Finland, 2003

[21] Skec V., Macon J.S., Susac M., Jokic D., Rajdic D., Macon D., Influence of Oral Hygiene on Oral Health of Recruits and Professionals in the Croatian Army, Mil Med, 2006, 171, 1006-1009

[22] Hopcraft M.S., Morgan M.V., Dental caries experience in a young adult military population, Aus Dent J, $2003,48,125-129$

[23] Muhvic-Urek M., Uhac I., Vuksic-Mihaljevic Z., Leovic D., Blecic N., Kovac Z., Oral health status in war veterans with post-traumatic stress disorder, J. Oral Rehabil, 2007 , 34, 1-8 